years; mean RA duration, 7.7 years; and $82.7 \%$ seropositive -similar between treatment groups. Baseline CS was less frequent in the mono vs combo group ( $41.1 \%$ vs $51.2 \%)$; however, the mean prednisone equivalent daily dose was similar (6.6 vs $6.5 \mathrm{mg} /$ day, respectively). Pts who continued TCZ to week 24 based on Kaplan-Meier estimates $(95 \% \mathrm{Cl})$ were $79.3 \%(74.7 \%>83.2 \%)$ for mono and $85.6 \%(83.7 \%>87.3 \%)$ for combo. DAS28 scores decreased comparably from baseline to week 24 in both groups (mean change: mono -3.40 and combo $-3.46)$, with no significant difference between groups $(P=0.61)$. Results were similar for the Clinical Disease Activity Index (CDAl, mean change by week 24: -23.5 and -23.8 , with no significant difference between groups: $P=0.42$ ). The proportion of pts who achieved DAS28 or CDAl-based remission, low disease activity or ACR20/50/70/90 responses was similar between groups (Figure 1). In all, $18.2 \%$ of pts withdrew; $6.4 \%$ did so for safety reasons (mono $9.1 \%$, combo $5.8 \%$ ). AE rates were similar between groups (Table). Serious AE (SAE) rates were 14.6/100 PY (mono: 22.8/100 PY, combo: 12.8/100 PY). Serious infection and infestation rates were 3.6/100 PY (mono: 4.0/100 PY, combo: 3.5/100 PY) similar between groups. Six deaths occurred (0.64/100 PY), 1 in the monotherapy group (0.57/100 PY) and 5 in the combination (0.65/100 PY) group.

Figure 1: DAS28 and CDAI Disease Activity and ACR Responses*

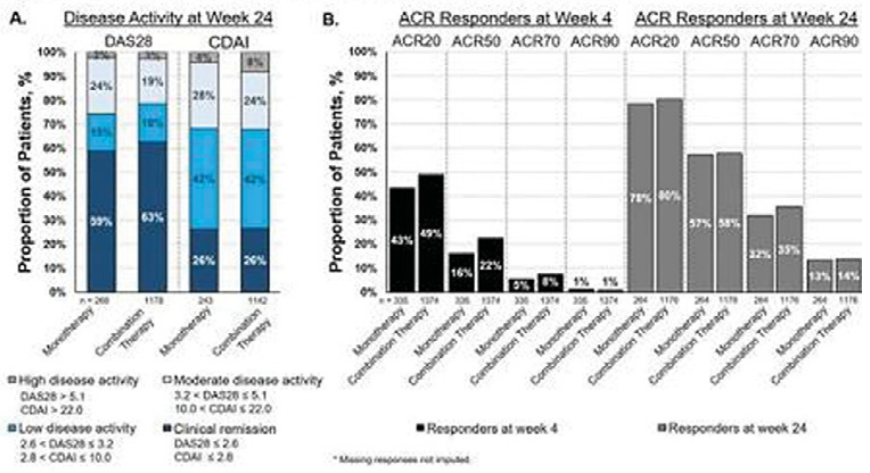

Table: Summary of Relevant Adverse Events

\begin{tabular}{|c|c|c|c|c|}
\hline & & $\begin{array}{c}\text { Total } \\
\text { Population } \\
(\mathrm{N}=1804 ; 943.3 \mathrm{PY})\end{array}$ & $\begin{array}{c}\text { Monotherapy } \\
(\mathrm{n}=353 ; 175.7 \mathrm{PY})\end{array}$ & $\begin{array}{l}\text { Combination Thorapy } \\
(\mathrm{n}=1451 ; 767.6 \mathrm{PP})\end{array}$ \\
\hline \multirow{2}{*}{$\begin{array}{l}\text { Adverse } \\
\text { events }\end{array}$} & $\begin{array}{l}\text { Total patients with } \\
\text { Z1 } A E, n(\%)\end{array}$ & $1508(83.6 \%)$ & $282(79.9 \%)$ & $1228(84.5 \%)$ \\
\hline & $\begin{array}{l}\text { Rate of AEs per } \\
100 \text { PY }\end{array}$ & 622.4 & 622.1 & 622.5 \\
\hline \multirow{2}{*}{$\begin{array}{l}\text { Serious } \\
\text { adverse } \\
\text { events }\end{array}$} & $\begin{array}{l}\text { Total patients with } \\
\text { z } 1 \mathrm{SAE}, \mathrm{n}(\%)\end{array}$ & $105(5.8 \%)$ & $29(82 \%)$ & $76(5.2 \%)$ \\
\hline & $\begin{array}{l}\text { Rate of SAES per } \\
100 \text { PY }\end{array}$ & 14.6 & 22.8 & 12.8 \\
\hline \multirow{2}{*}{$\begin{array}{l}\text { Serious } \\
\text { infections and } \\
\text { infestations }\end{array}$} & $\begin{array}{l}\text { Total patients with } \\
\text { ₹ } 1 \mathrm{SAE}, \mathrm{n}(\%)\end{array}$ & $27(1.5 \%)$ & $6(1.7 \%)$ & $21(1.4 \%)$ \\
\hline & $\begin{array}{l}\text { Rate of SAEs per } \\
100 \text { PY }\end{array}$ & 3.6 & 4.0 & 3.5 \\
\hline $\begin{array}{l}\text { Withdrawals } \\
\text { due to } \\
\text { insufficient } \\
\text { therapeutic } \\
\text { response }\end{array}$ & $\begin{array}{l}\text { Total patients with } \\
=1 \text { reason, } \mathrm{n}(\%)\end{array}$ & $40(2.2 \%)$ & $9(2.5 \%)$ & $31(2.1 \%)$ \\
\hline $\begin{array}{l}\text { Withdrawals } \\
\text { due to safety } \\
\text { reasons' }\end{array}$ & Patents, $n(\%)$ & $116(6.4 \%)$ & $32(9.1 \%)$ & $84(5.8 \%)$ \\
\hline \multirow{2}{*}{ Deaths } & $\begin{array}{l}\text { Number of deaths, } \\
\mathrm{n}(\%)\end{array}$ & $6(0.3 \%)$ & $1(0.3 \%)^{r}$ & $5(0.3 \%):$ \\
\hline & $\begin{array}{l}\text { Rate of deaths per } \\
100 \mathrm{PY}\end{array}$ & 0.64 & 0.57 & 0.65 \\
\hline
\end{tabular}

- Deaths, anaphylaxis and hypersensitivity reactions not included.

Coronary artery disease.

Myocardial infarction, pneumonia, pulmonary fibrosis, sepsis, septic shock

Note: TOZURA trial numbers: NCTO1995201. NCT02046603. NCT02011334, NCT02031471. NCT02001987, NCT01941095, NCT01941940, NCT02046616, NCT01988012, NCT01987479, NCT01951170.

Conclusions: TCZ-SC demonstrated convincing and comparable efficacy as mono- and combination therapy in pts with RA as was previously observed with TCZ-IV. The safety profile of TCZ-SC is consistent with the known safety profile of TCZ as monotherapy and in combination with csDMARDs.

Acknowledgements: Funded by F. Hoffmann-La. Roche, Ltd.

Disclosure of Interest: E. Choy Grant/research support from: F. Hoffmann-La Roche, Chugai Pharmaceutical, Consultant for: F. Hoffmann-La Roche, Chugai Pharmaceutical, Speakers bureau: F. Hoffmann-La Roche, Chugai Pharmaceutical, R. Caporali Consultant for: AbbVie, Bristol-Myers Squibb, F. Hoffmann-La Roche, UCB and MSD Pharmaceuticals, R. Xavier Consultant for: F. Hoffmann-La Roche, Pfizer, Janssen Pharmaceuticals, AbbVie, Eli Lilly and Company, Speakers bureau: F. Hoffmann-La Roche, Pfizer, Janssen Pharmaceuticals, Abbvie, Eli Lilly and Company, B. Fautrel: None declared, R. Sanmarti: None declared, C. Bernasconi Employee of: F. Hoffmann-La Roche (contractor), A. Pethö-Schramm Employee of: F. Hoffmann-La Roche

DOI: 10.1136/annrheumdis-2017-eular.1615

\section{SAT0200 BIOLOGIC THERAPY RETENTION IN RHEUMATOID ARTHRITIS (RA) PATIENTS (PTS) ACCORDING TO THE MOSCOW ARTHRITIS REGISTRY (MAR)}

G. Lukina ${ }^{1}$, E. Koltsova ${ }^{2}$, E. Schmidt ${ }^{3}$, E. Zhilyaev ${ }^{4} .{ }^{1}$ V.A. Nasonova Research Institute of Rheumatology, Moscow Clinical Scientific Center: ${ }^{2}$ Research Institute of the Organization of health and healthcare management; ${ }^{3}$ City Clinical Hospital 1 named after N.I. Pirogov; ${ }^{4}$ Russian Medical Academy of continuing professional education, CJSC "European Medical Center", Moscow, Russian Federation

Background: The use of biologics significantly improved results of the therapy of RA pts who did not achieve the target disease activity level on traditional DMARDS treatment. However the biologic therapy is in many cases withdrawn due to inefficacy or side effects (seldom because of sustained remission). Retention on treatment is a good integral index of efficacy and safety of biologics used in the real clinical practice.

Objectives: To assess the treatment survival of various biologics in RA pts in the real clinical practice.

Methods: Patients from MAR with RA receiving biologics were enrolled. Cases with missed results were excluded. A Cox proportional hazards regression model was used to determinethe predictors of the treatment discontinuation risk. Comparison of biologics retention rates for different biologicswas performed by means of Kaplan-Meier survival curves. Bonferroniadjustment was applied because of multiplicity of comparisons.

Results: 306 RA pts (mean age 54,5 years, mean age of disease onset 39,6 years, $86,5 \%$ women, $18 \%$ smokers, RF-positive $83,7 \%$ ) were included in the study and 394 treatment courses (263 retrospective and 131 prospective) were analyzed. It was shown that significant independent predictors of discontinuation risk were: the biologic drug, the sequence number of the biologic drug in the patient and the age of RA onset. Risk of withdrawal was minimal by the use of the first biologic and increased by administration of the next ones. It also increased in pts with late onset of RA. Mass body index, age of the patient and the dose of methotrexate did not show significant correlations. Abatacept (ABA) demonstrated significant superiority over adalimumab (ADA) $(p<0.001)$, infliximab (INF) $(p<0.001)$, rituximab (RTM) $(p=0.004)$ and etanercept $(E T A)(p=0.035)$ when they was used as the first biologic drug. The treatment survival of tocilizumab was significantly higher compared to INF $(p=0.02)$. As a second-line biological therapy ADA was maintained significantly longer than the INF $(p=0.048)$.

Conclusions: Results of the real clinical practice trial show the significant differences in the retention rates of some biologics. It is reasonable to take these differences into consideration by the planning of the biologic treatment of RA pts. Disclosure of Interest: None declared

DOI: 10.1136/annrheumdis-2017-eular.3657

\section{SAT0201 ABATACEPT BUT NOT TNF INHIBITORS BLOCK AUTOANTIBODY-MEDIATED CYTOKINE PRODUCTION BY MONOCYTES}

A. Bozec ${ }^{1}$, Y. Luo ${ }^{2}$, C. Engdahl ${ }^{1}$, C. Figueiredo ${ }^{3}$, H. Bang ${ }^{4}$, G. Schett ${ }^{1}$ ${ }^{1}$ University of Erlangen-Nuremberg, Erlangen, Germany; ${ }^{2}$ University of Chengdu, Chengdu, China; ${ }^{3}$ Universidade de São Paulo, Sao Paulo, Brazil; ${ }^{4}$ Orgentec Inc., Mainz, Germany

Background: The anti-inflammatory effect of abatacept (CTLA4-lg) is most pronounced in patients with high-titer autoantibodies (including anti-citrullinated protein antibodies, ACPA, and rheumatoid factor, RF) even exceeding the effect of TNF inhibitors (TNFi) ${ }^{1}$. Considering that autoantibodies trigger inflammatory cytokine production by monocytes ${ }^{2}$ and that abatacept bind to monocytes influencing their functional state ${ }^{3}$ we hypothesized that abatacept, in contrast to TNFi, may effectively inhibit the production of several different cytokines by ACPA-or RF-challenged monocytes.

Objectives: (i) To test whether abatacept inhibits the production of TNFa, IL-1b, IL-6 and IL-8 by monocytes exposed to ACPA or RF, (ii) to compare these effects of abatacept with those of TNFi and (iii) to investigate whether the effect of abatacept on cytokine production is based on IDO induction in monocytes.

Methods: CD68+ monocytes were isolated from peripheral blood and stimulated with MCSF for 24 hours before exposing them to random IgG alone (negative control), $10 \mathrm{mg} / \mathrm{mL}$ purified anti-citrullinated vimentin antibodies (ACPA), $10 \mathrm{mg} / \mathrm{mL}$ RF or LPS (positive control) in cell culture plates coated with citrullinated vimentin (to allow ACPA immune complex formation). ACPA and RF stimulation was done in the presence or absence of abatacept or TNF-antibody (adalimumab) with or without IDO inhibitor 1-MT. Supernatants were analyzed for four key pro-inflammatory cytokines TNFa, IL-1b, IL-6 and IL-8 by cytokine array (R\&D Proteome Profiler) after 24h.

Results: Exposure to ACPA or RF dramatically induced the production of TNFa (20 fold and 27-fold, respectively) IL-1b (each 4-fold), IL-6 (12-fold and 11-fold, respectively) IL-8 (43-fold and 30-fold, respectively) in human monocytes. Abatacept significantly inhibited this up-regulation of inflammatory cytokine production with TNFa reduced by $79 \%$, IL- 1 b by $74 \%$, IL-6 by $88 \%$ and IL-8 by $83 \%$. In contrast, TNFi did not influence autoantibody-induced production of IL-1b, IL- 6 and IL-8. Inhibition of IDO by 1-MT reversed the effect of abatacept and unlocked cytokine production in the presence of ACPA and RF.

Conclusions: These data show that abatacept interferes with autoantibody mediated cytokine production by induction of IDO. The fact that several different 
effector cytokines are inhibited simultaneously may explain the strong antiinflammatory effect of abatacept in RA patients with high-titer ACPA and RF. References:

[1] Sokolove J, et al. Impact of baseline anti-cyclic citrullinated peptide-2 antibody concentration on efficacy outcomes following treatment with subcutaneous abatacept or adalimumab: 2-year results from the AMPLE trial. Ann Rheum Dis. 2016;75:709-14.

[2] Clavel C, et al Among human macrophages polarised to different phenotypes, the M-CSF-oriented cells present the highest pro-inflammatory response to the rheumatoid arthritis-specific immune complexes containing ACPA. Ann Rheum Dis. 2016;75:2184-2191.

[3] Bozec A, et al. T cell costimulation molecules CD80/86 inhibit osteoclast differentiation by inducing the IDO/tryptophan pathway. Sci TransI Med. 2014;6:235ra60.

Acknowledgements: This project was supported by an unrestricted research grant from BMS and the IMI project BTCure.

Disclosure of Interest: None declared

DOI: 10.1136/annrheumdis-2017-eular.4363

\section{SAT0202 EFFICACY AND SAFETY OF SARILUMAB MONOTHERAPY VERSUS ADALIMUMAB MONOTHERAPY IN PATIENTS WITH ACTIVE RHEUMATOID ARTHRITIS IN THE PHASE 3 MONARCH STUDY, INCLUDING SUBPOPULATIONS}

G.R. Burmester ${ }^{1}$, Y. Lin ${ }^{2}$, E.K. Mangan ${ }^{3}$, H. van Hoogstraten ${ }^{2}$, T. Kimura ${ }^{3}$, J.I. Vargas ${ }^{4}$, E.B. Lee ${ }^{5} .{ }^{1}$ Charité - University Medicine Berlin, Free University and Humboldt University Berlin, Berlin, Germany; ${ }^{2}$ Sanofi Genzyme,

Bridgewater; ${ }^{3}$ Regeneron Pharmaceuticals, Inc, Tarrytown, United States

${ }^{4}$ Quantum Research, Puerto Varas, Chile; ${ }^{5}$ Seoul National University College of Medicine, Seoul, Korea, Republic Of

Background: Efficacy and safety of sarilumab + csDMARDs in RA patients have been demonstrated.

Objectives: To compare sarilumab monotherapy with adalimumab monotherapy in the ITT population of adults with active RA from MONARCH (NCT02332590) and across predefined subgroups.

Methods: Adults ( $\mathrm{N}=369)$ intolerant of, inappropriate for, or inadequate responders (IR) to MTX (per investigator judgment) received SC sarilumab $200 \mathrm{mg}$ q2w or adalimumab $40 \mathrm{mg}$ q2w monotherapy. The primary endpoint was change from baseline in DAS28-ESR at wk 24. Consistency of treatment response (sarilumab vs adalimumab) for this endpoint was assessed in prespecified subpopulations.

Results: At wk 24, sarilumab was superior to adalimumab in change from baseline (BL) in DAS28-ESR $(-3.3$ vs $-2.2 ; P<0.0001)$. Sarilumab-treated patients achieved significantly higher rates of ACR20 response $(71.7 \%$ vs $58.4 \% ; P=0.0074)$ and greater improvement in HAQ-DI (-0.6 vs $-0.4 ; P=0.0037)$ and CDAI (-28.9 vs -25.2 ; nominal $P=0.0013$ ) vs adalimumab-treated patients. Extent of treatment effect with sarilumab vs adalimumab in change from baseline in DAS28-ESR at wk 24 was generally consistent $(P>0.05)$ across subgroups; significant treatment-bysubgroup interactions were observed for body mass index $(P=0.047)$ and baseline CRP $(P=0.006)$ (Figure). The magnitude of treatment effect for DAS28-ESR was greater in patients with lower BMI and higher baseline CRP. Treatment effect was generally similar for other efficacy endpoints assessed, including ACR20, HAQ-DI, and CDAl. Clinical and functional responses in RF+/ACPA+, RF+/ACPA-, RF/ACPA+, and RF-/ACPA- patients were similar to overall study results. Incidence of AEs was similar in both groups, including incidences of infections and serious infections. The most common AEs were neutropenia and injection site erythema (sarilumab) and headache and worsening of RA (adalimumab).

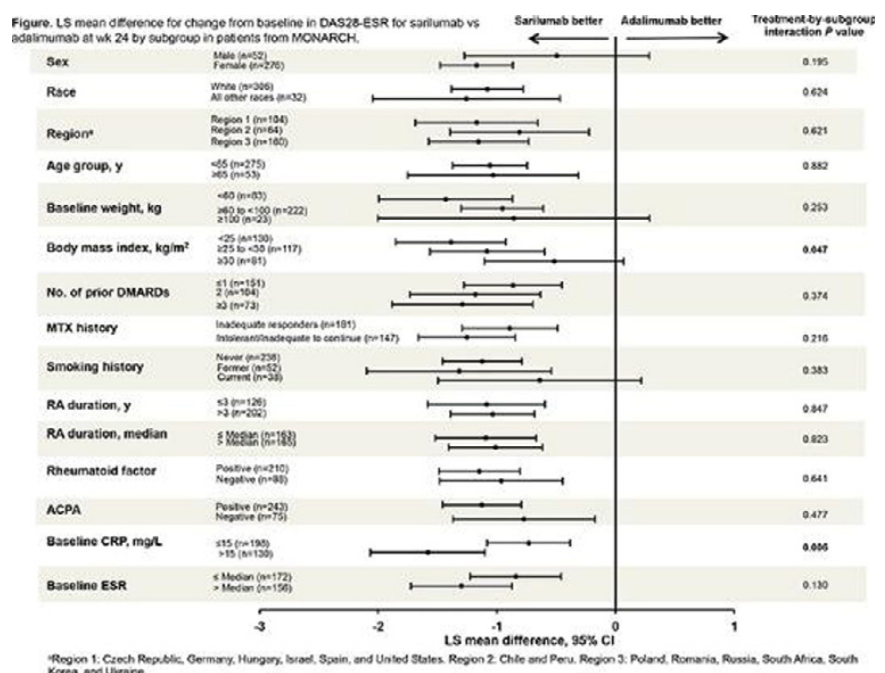

Conclusions: Sarilumab monotherapy demonstrated superiority to adalimumab monotherapy in the ITT population in change from baseline in DAS28-ESR. The extent of treatment effect with sarilumab vs adalimumab was generally consistent across subpopulations. Overall incidences of AEs and serious AEs and rates of infection and serious infection were similar between groups.

Acknowledgements: This study was sponsored by Sanofi Genzyme and Regeneron Pharmaceuticals, Inc. Medical writing support was provided by MedThink SciCom and funded by Sanofi Genzyme and Regeneron Pharmaceuticals, Inc. Disclosure of Interest: G. Burmester Grant/research support from: AbbVie, Bristol-Myers Squibb, Medlmmune, Merck, Pfizer, Roche, and UCB, Consultant for: AbbVie, Bristol-Myers Squibb, Medlmmune, Merck, Pfizer, Roche, and UCB, Speakers bureau: AbbVie, Bristol-Myers Squibb, Merck, Pfizer, Roche, and UCB, Y. Lin Shareholder of: Sanofi Genzyme, Employee of: Sanofi Genzyme, E. Mangan Shareholder of: Regeneron Pharmaceuticals, Inc, Employee of: Regeneron Pharmaceuticals, Inc, H. van Hoogstraten Shareholder of: Sanofi Genzyme, Employee of: Sanofi Genzyme, T. Kimura Shareholder of: Regeneron Pharmaceuticals, Inc, Employee of: Regeneron Pharmaceuticals, Inc, J. Vargas Grant/research support from: Roche, Bristol-Myers Squibb, and Pfizer, Speakers bureau: Bristol-Myers Squibb, E. Lee Consultant for: Pfizer

DOI: 10.1136/annrheumdis-2017-eular.4540

\section{SAT0203 SIGNIFICANCE OF EXTENSION OF TOCILIZUMAB INFUSION INTERVALS FROM 4 WEEKS TO 6 WEEKS IN RA PATIENTS WHO HAD SHOWN GOOD RESPONSE TO 4 WEEK INTERVALS}

H. Uda ${ }^{1}$, K. Shigematsu ${ }^{2}$, O. Saiki ${ }^{1,3} \cdot{ }^{1}$ Rheumatology; ${ }^{2}$ Orthopedics,

Higashiosaka City Medical Center, Higashiosaka; ${ }^{3}$ Internal Medicine, Shiraishi Hospital, Imabari, Japan

Background: A period of 4 weeks (w) has been recommended as tocilizumab (TCZ, $8 \mathrm{mg} / \mathrm{kg}$ ) infusions. However, we found that 5 or $6 \mathrm{w}$ intervals were also effective in more than $90 \%$ of RA patients with low disease activity (LDA) at $4 \mathrm{w}$ intervals (1).

Objectives: We conducted the study to investigate the significance of extension of intervals from $4 \mathrm{w}$ to $6 \mathrm{w}$. We compared, in the same patients, the clinical features such as diseases activity, major and minor side reactions between at $4 \mathrm{w}$ and at 6w. Moreover, we also considered the mechanisms.

Methods: This was a retrospective observational study. Among RA patients who had shown LDA with TCZ infusions at $4 w$ intervals, the patients who could extend the intervals from $4 \mathrm{w}$ to $6 \mathrm{w}$ with LDA for more than 2 years without changing the doses of oral medicines were enrolled. In the same patients, we compared the events of serious and common side reactions between at $4 \mathrm{w}$ and $6 \mathrm{w}$ intervals. We examined the course of the levels of total cholesterol (TCHO), triglyceride (TG), and platelet (PLT) counts. We also examined the levels of serum trough TCZ and IL-6.

Results: Among 120 patients who maintained LDA at $4 \mathrm{w}$ intervals, more than $60 \%$ of patients maintained LDA at $6 \mathrm{w}$ intervals. When we compared the disease activity of $6 w$-responders between at $4 w$ and $6 w$-intervals, all parameters reflecting the disease activities such as CRP and DAS28CRP score at $6 \mathrm{w}$ intervals were elevated significantly, but were still within LDA. At $4 w$ intervals, serious adverse events were occurred as much as 11 cases during 2 years. At $6 \mathrm{w}$ intervals, however, they were decreased to 3 cases only in the same period. The common adverse events such as general fatigue, nausea, and dizziness occurred frequently at $4 \mathrm{w}$ intervals in most of the patients. At $6 \mathrm{w}$ intervals, these common adverse events were decreased significantly. At $4 \mathrm{w}$ intervals, the levels of $\mathrm{TCHO}$ and $\mathrm{TG}$ were elevated significantly. At $5 \mathrm{w}$ and $6 \mathrm{w}$ intervals, however, they were decreased accordingly. At $6 \mathrm{w}$ intervals, they were within normal limits. In most of patients, the levels of PLT counts were decreased significantly at $4 \mathrm{w}$ intervals. At $5 \mathrm{w}$ and $6 \mathrm{w}$ intervals, however, they were increased gradually. When TCZ were infused at $4 \mathrm{w}$ intervals, the serum trough TCZ levels were around 10 $\mu \mathrm{g} / \mathrm{mL}$. In contrast, they became undetectable when extended to $5 \mathrm{w}$, and it is obvious that the trough TCZ levels of $6 \mathrm{w}$ were lower than $5 \mathrm{w}$. The levels of IL-6 were significantly high at $4 \mathrm{w}$-intervals, but the levels of IL-6 were decreased to less than $10 \mathrm{pg} / \mathrm{mL}$ at $5 \mathrm{w}$-intervals.

Conclusions: The present study provide evidence that more than half of RA patients who showed good response to TCZ infusions at $4 \mathrm{w}$ could extend the intervals to $6 \mathrm{w}$. By extension of intervals to $6 \mathrm{w}$, major and minor side reactions were reduced significantly, and the levels of TG, TCHO and PLT were also normalized with sustaining LDA, suggesting that the dose of TCZ $(8 \mathrm{mg} / \mathrm{kg})$ at $4 \mathrm{w}$ intervals might be excessive in some patients. Taken together, we should be careful for deciding the intervals of TCZ infusion in each patient.

References:

[1] Saiki O, Uda H. Successful extension of tocilizumab infusion intervals from 4 weeks to 6 or 5 weeks in $90 \%$ of RA patients with good response to 4 weeks intervals. Clin Exp Rheumatol (2017 in press).

Disclosure of Interest: None declared

DOI: 10.1136/annrheumdis-2017-eular.3602 